\title{
Technical Teaching and Training of Volleyball
}

\author{
$\mathrm{He} \mathrm{Li}$ \\ Jiangxi College of Foreign Studies
}

\section{Keywords: Volleyball; Teaching; Technology}

\begin{abstract}
Volleyball is a kind of adversarial, collective and technical sports. There are various factors promoting the development of volleyball, including economic development, technical advancement, changes of rules and emergence of new tactics, etc. Economic development has provided material basis for the conduction of volleyball, the progress of science and technology has provided theoretical support for the development of volleyball, and changes of rules can make volleyball more competitive and enjoyable while the emergence of new tactics can great enrich the connotation of volleyball and make it more attractive and full of vitality. However, the current conduction of volleyball is not so optimistic and still lags behind the expected goal, so in order to narrow the gap, it is necessary to comprehensively analyze the current volleyball education at colleges and universities and propose some suggestions to improve the current volleyball teaching techniques.
\end{abstract}

\section{Introduction}

Volleyball originated in the United States and was invented by a sports staff named Morgan (William • G • Morgan) from Holyoke, Massachusetts (formerly known as MA) in 1895. At that time, basketball and volleyball were very popular. Mr. Morgan thought that basketball was too intense but volleyball had too small amount of exercise, so he would like to seek an indoor entertainment exercise with appropriate amount of exercise, full of fun and suitable for all ages. Therefore, he considered playing the already popular volleyball indoors at the basketball field with hands. In the beginning, he hanged the tennis net at the basketball court to play the game just like using the basketball net to playing the volleyball.

Volleyball is a very popular sport, and its development is full of constantly innovation and maturity of techniques and tactics. This paper analyzes the innovation and development of volleyball tactics, and it is just such constant innovation and developments of tactics that greatly enriches the connotation of volleyball and make volleyball more attractive and full of vitality, inspiring people's enthusiasm in volleyball so as to better promote the development and popularity of volleyball.

Development of Volleyball. Ever since its birth, the development of volleyball can be roughly divided into three stages, and the development at each stage is closely related to the emergence of new tactics.

The Stage of Entertainment Volleyball. Volleyball originated in the United States in 1895, and at that time, it was just a means of entertainment for workers at their spare time. In the beginning, the basketball and tennis net were used in the game to prevent the ball from falling down on the ground, and people played volleyball just for fun and leisure, lacking the sense of competition. This stage is the infancy stage for volleyball, and the emergence of new entertainment greatly attracted more young people to participate in it, laying a foundation for the development of volleyball.

The Stage of Competitive Volleyball and Improved Techniques and Tactics. As proficiency increased, people are no longer satisfied with the simplest and most primitive way of playing the volleyball, but they gradually seek stimulation in playing volleyball. There is increasing mutual cooperation between teammates, and volleyball gradually enters the embryonic stage. At this time, serving a ball is just a form to start the game, and gradually develops into an aggressive technique. 


\section{Rapid Development Stage of Modern Volleyball}

With the rapid economic development and progress in science and technology, volleyball is becoming increasingly modern. Video, 3D analysis and other techniques are gradually widely applied into volleyball, further promoting the innovation of volleyball tactics. Especially since the 1980 s, there is a worldwide fever for volleyball, and in order to achieve good result, each team has been extensively gathering information and utilizing technological means to invent tactics suitable for them while combining their own characteristics.

Current Situation of Teaching Volleyball. The current situation of volleyball is not so optimistic and still lags far behind the expected goal, so in order to narrow this gap, it is necessarily to comprehensively analyze the current volleyball education at colleges and propose several suggestions to improve the current situation of volleyball education at colleges, which are shown as follows:

Problems in Teaching System and Unreasonable Teaching Contents. Sports lessons at primary and middle schools have not received enough attention, so college students have weak sports foundation as well as relatively poor physical fitness. In this regard, it is consistent in most colleges. Most volleyball education only teaches the simple serve, dig and pass, etc. and the teaching contents are relatively simple, lacking difficulty and entertainment. Some relevant contents are not taught, so this needs to be further improved.

Emphasizing the Improvement of Techniques and Tactics, Unconducive to the Overall Development of Students. Volleyball is one of the general courses at college as well as the normal sports course, and volleyball's own characteristics of being competitive and collective is gradually prominent, so teachers should pay more attention to teaching volleyball techniques and tactics, and regard assessment methods, students' mastery and sports scores as the main assessment basis without giving students too many quantitative assessment indicators.

Low Level of Scientific Research. Due to the restriction of traditional education system and guiding ideology like teaching skills, a lot of scientific research results that have been proved to be effective are just included into theoretical research and excluded from teaching practice, because scientific research results are not integral, but only solve issues of one aspect, such as teaching methods and teaching process.

\section{Technical Innovation in Teaching Volleyball}

Serve Technology Innovation. Service Player can be observed in the tee area relatively calmly the other location, select the other a poor transfer techniques, or using a weak position and strong attack, serve success rate technology, send the ball over the net, so in the course of the Serving Training the key to strengthen the psychological quality of training depends on the success of the tee is to master proficiency and mental state and stability of the game when a spot on serve the only reason why the study serve errors caused only - to better identify the problems, develop training programs that serve success rate has been further improved.

Innovation in Digging. With the continuous innovation of the service techniques, the techniques are constantly evolving. In the 1950s has appeared in the tiger's mouth digging, embrace a boxing digging and Alice wrist digging; in the early 1960s, due to the prevalence of floating ball, forearm digging technology. With the development of other tactics, dig also appeared suitable for receiving all serving, spiking and blocking back ball method, such as digging positive hands, body side digging, back cushion, block ball, step digging, hassock, let pad, roll digging, attacks before digging, digging with a single hand, lateral digging, digging, etc.

Innovation and Development of Passing. Pass plays the role of organizing attack in volleyball matches. Good pass technique can produce more effective attack so that the opposite side is unable to guard. Therefore, a team setter is also known as the soul of the team. With the serving, spiking technology innovation and the strength of the ball, speed continues to increase; passing technology is adapted to the game at the same time continuous development and innovation. 


\section{Conclusion}

Appropriate additional soft volleyball sports in physical education, especially for girls to promote the project can be greatly improved in the girls psychologically, quality, multi-ball, get the ball to lay the psychological needs largely met, and taste success, interest in bringing happiness, hard-working athlete experience, courage to fight the spirit of patriotism and strong will of character, which is the future of the students into the community, hard work of great benefit, but teachers can also be used between classes, after-school teaching Some technical points soft volleyball in training groping summed up a set of effective experience, all this can undoubtedly play a further role in promoting mass sports.

\section{References}

[1] Wang H. The Applied Research on Participation Method in the Volleyball Technique Teaching [J]. Bulletin of Sport Science \& Technology, 2008.

[2] Zhang W. Discussion on Classify Training of Volleyball Technique [J]. Journal of Nanjing Institute of Physical Education, 2008.

[3] Zhou D, Gao F, Zheng H. Experimental Research on Development of Soft Volleyball Technique and Reform of its Rules [J]. Journal of Beijing University of Physical Education, 2002.

[4] LuWei. Application of Target Setting to Volleyball Technique Teaching [J]. Journal of Beijing Vocational \& Technical Institute of Industry, 2003.

[5] Li Zaixing. On Optimization of Teaching in Volleyball Technique and Tactics [J]. Sports Science Research, 2001.

[6] Wang J. Elementary Analysis on Volleyball Technique and Strategy Innovations [J]. Sichuan Sportsence, 2000.

[7] Zeng L, Liu Z W, Luo W F. Application Study on Attribution Theory in Volleyball Technique Teaching [J]. Journal of Hunan Institute of Humanities Science \& Technology, 2006.

[8] Hou Y L. A study on the method of Assistant Force in Volleyball Technique Learning [J]. Journal of Guangzhou Physical Education Institute, 2002.

[9] Xiao, Jiayin. "The Application of the Motivation Mechanism to the Volleyball Technique Teaching Practice." Journal of Wuhan Institute of Physical Education (1997).

[10]Xiao Y. Experimental Study of Group Cooperative Learning Teaching Method in Volleyball Technique Class Teaching of Sports Specialty in Colleges and Universities [J]. Academic Journal of Shaolin \& Taiji, 2013.

[11]Zhang C, Yang G L. The studying of the students' egotism attribution bias on volleyball technique learning of the teachers' university [J]. Journal of Nanjing Institute of Physical Education, 2003.

[12]Xia G. The New FIVB Rule's Influence on Volleyball Technique And Tactics And the Countermeasure [J]. Journal of Physical Education of Shanxi Teachers University, 2001. 